\title{
Proyecto Callejero: um panorama da gráfica popular na América Latina - mapeamento de iniciativas de registro da memória gráfica popular
}

Proyecto Callejero: an overview of vernacular graphics in Latin Americamapping of initiatives for recording vernacular graphic memory

\author{
Maria de Fátima Waechter Finizola \& Simon Ibañez Nuñez
}

\begin{abstract}
design vernacular, gráfica popular, América Latina
Informações efêmeras de caráter popular figuram na paisagem visual de diversas cidades da América Latina. Estas têm o papel de identificar, anunciar e vender produtos, serviços e ideias. Essa produção, denominada de gráfica popular, caracteriza-se como um gênero visual que tem se desenvolvido em diversos países, à revelia do mundo digital, por meio de técnicas artesanais transmitidas de geração em geração por artífices e artistas populares. Várias iniciativas têm surgido desde a década de 1990 com a finalidade de estudar e registrar essa produção, no sentido de reconhecer a sua importância como parte da tradição e cultura visual latino-americana. No entanto, ainda há uma carência de estudos comparativos entre as diversas formas de manifestação dessa linguagem popular a fim de investigar a origem dessa tradição, bem como as semelhanças e idiossincrasias desses artefatos em localidades distintas. Nesse sentido, este projeto se propõe a reunir impressões de investigadores de 14 países da América Latina sobre a gráfica popular, a fim de traçar um panorama dessa prática tão presente na região. Neste artigo, especificamente, apresentamos os dados coletados na fase de mapeamento do projeto, que apontam para a consolidação de um movimento de registro e resgate da gráfica popular latina nas últimas décadas.
\end{abstract}

vernacular design, vernacular graphics, Latin America

Ephemeral information with popular characteristics appears in the visual landscape of many cities of Latin America. They have the role of identifying, advertising and selling products, services and ideas. These activities, known as "gráfica popular", are characterized as a visual genre that has developed in many countries, in the absence of the digital world, using artisanal techniques transmitted from generation to generation by popular craftsmen and artists. Several initiatives have arisen since the 1990s with the purpose of studying and registering these activities, in order to recognize its importance as part of the tradition and visual culture of Latin America. However, there is still a lack of comparative studies about the different forms of manifestation of this popular language with the objective of investigating the origins of this tradition, and also the similarities and idiosyncrasies of these artifacts in different locations. In this sense, the propose of this project is gathering the impressions of researchers from 14 countries of Latina America on vernacular graphics in order to draw a panorama of this practice so present in this region. In this paper, we present the data collected during the mapping project phase that point to the consolidation of an effort to record and recover Latin vernacular graphics in the last decades.

\section{Introdução}

Informações efêmeras de caráter popular figuram na paisagem visual de diversas cidades da América Latina. Estão presentes nos muros das cidades, nas periferias, nas feiras livres, na beira das estradas, entre outros locais, e têm o papel de identificar, anunciar e vender de tudo um pouco - frutas e verduras, picolés e sorvetes - e também de oferecer os mais diversos serviços - costura, pintura, borracharia, cabeleireiro, sapataria, amolador, etc. Essa produção informal, denominada amplamente na América Latina de gráfica popular, caracteriza-se como um gênero visual que durante anos tem se desenvolvido à revelia do mundo digital por meio de técnicas artesanais transmitidas de geração em geração por artífices e artistas populares, como, por exemplo, os pintores de letras.

Trata-se ainda de uma linguagem gráfica que é produzida majoritariamente por profissionais

Anais do $9 \%$ CIDI e 9 CONGIC

Luciane Maria Fadel, Carla Spinillo, Anderson Horta,

Cristina Portugal (orgs.)

Sociedade Brasileira de Design da Informação - SBDI

Belo Horizonte | Brasil | 2019

ISBN $978-85-212-1728-2$
Proceedings of the 9th CIDI and 9th CONGIC

Luciane Maria Fadel, Carla Spinillo, Anderson Horta,

Cristina Portugal (orgs.)

Sociedade Brasileira de Design da Informação - SBDI

Belo Horizonte | Brazil | 2019

ISBN 978-85-212-1728-2 
provenientes de classes populares e que, em muitos casos, não tiveram acesso ao processo de ensino formal em design. Em geral, também é identificada como uma manifestação cultural não oficial, muitas vezes pouco valorizada e não reconhecida pela história do design, e que hoje se encontra ameaçada pela introdução das tecnologias de impressão digital no mercado da comunicação visual e propaganda.

Há alguns anos, diversas iniciativas têm surgido na América Latina em busca de registrar essa produção na forma de projetos de pesquisa ou projetos culturais que objetivam estudar e difundir essas tradições e práticas populares em cada uma de suas localidades. No entanto, essas pesquisas se encontram dispersas em publicações impressas ou páginas da Internet, tornando-se, às vezes, de difícil acesso para a leitura e a análise comparativa de dados.

Tendo em vista essa problemática, o projeto de pesquisa aqui apresentado se propõe a traçar um panorama inicial da produção gráfica popular na América Latina, sob o ponto de vista dos aspectos formais e técnicos dessas práticas, a partir de dados coletados por meio de um processo de pesquisa colaborativo junto a uma rede de pesquisadores de reconhecida atuação nessa área em seus respectivos países.

Nesse sentido, o objetivo geral deste projeto é contribuir e fortalecer o registro da diversidade da cultura gráfica popular latino-americana por meio de uma pesquisa panorâmica que busca compreender as características dessa produção e dos artefatos reconhecidos como parte desse universo nos países da América Latina.

Como objetivos específicos, propomos:

- Mapear pesquisadores e movimentos de resgate da gráfica popular com trabalho expressivo na América Latina e selecionar uma amostra inicial de representantes de 14 países.

- Compreender as características da gráfica popular predominantes em cada uma destas localidades por meio de relatos e entrevistas cedidas pelos pesquisadores colaboradores e profissionais da área.

- Formar banco de imagens das expressões da gráfica popular na América Latina.

- Investigar e analisar as características gráficas das manifestações catalogadas, buscando identificar suas similaridades e particularidades.

- Investigar os processos técnicos empregados para a produção artesanal desses artefatos.

- Publicar um livro como resultado do projeto.

Esta pesquisa surge da parceria inicial entre pesquisadores do Brasil e do Chile e hoje está integrada às atividades do grupo de pesquisa registrado no CNPq denominado LDGraf: Linguagens do Design Gráfico, desenvolvido no Centro Acadêmico do Agreste da UFPE.

\section{Conceitos iniciais acerca da gráfica popular}

Segundo Ucrós (2012), o termo gráfica popular basicamente se refere aos projetos gráficos criados por designers gráficos "não profissionais" para ajudar a anunciar produtos e serviços, sendo assim produzidos por pessoas que não têm acesso a computadores, consequentemente se caracterizando como um gênero visual que, durante anos, tem desenvolvido a sua forma fora do reino do design digital. Nota-se que se trata de um termo bastante difundido, principalmente nos países latino-americanos hispanofalantes, para designar os artefatos de comunicação popular gráfica presentes no ambiente urbano e seus elementos visuais, tais como tipografias, imagens, ícones, cores, grafismos.

$\mathrm{Na}$ América Latina, é, por definição, a linguagem gráfica produzida pela classe trabalhadora mais pobre, por pessoas que não tiveram um amplo acesso à educação e cuja história familiar e modo de vida têm seguido caminhos muitas vezes diferentes dos das elites (Ucrós, 2012).

Checa-Artasu \& Rodríguez (2009, p. 4) observam que a gráfica popular é um fenômeno que podemos considerar quase global, que mostra a diversidade cultural do planeta.

De forma mais abrangente, podemos identificar essa produção como parte integrante do 
que denominamos de design vernacular, tendo em vista a definição proposta por Farias (2011):

No design gráfico e na tipografia, podemos definir artefatos vernaculares como produtos de práticas de design desenvolvidas antes ou a despeito da instituição das escolas de design modernistas, principalmente por artistas anônimos, e no contexto do comércio. Placas pintadas à mão e impressos efêmeros (tais como cartazes e embalagens) são exemplos típicos de design gráfico vernacular. (Farias, 2011, p. 167).

Notamos, no entanto, que há duas formas distintas de tratar produção gráfica vernacular de acordo com a sua região de origem. Nos países europeus e nos Estados Unidos, por exemplo, ela nos remete a uma tradição nostálgica do passado pré-industrial, enquanto, na América Latina e em alguns países dos continentes africano e asiático, esta ainda é uma tradição que se mantém viva e que acontece em paralelo com a produção do design formal.

Para compreender esse comportamento, podemos tomar como referência a prática do letreiramento comercial elaborado por processos artesanais pelos pintores de letras. ChecaArtasu \& Rodríguez (2009) refletem sobre o início da prática desse ofício:

O pintor de letras tomou as cidades do velho continente desde meados do século XVII, consolidando, assim, um ofício que prevalecerá até início do século XX [...]. A crescente expansão de suportes, técnicas e conceitos levou ao desaparecimento do que temos definido como gráfica popular no mundo ocidental, imerso plenamente depois da Segunda Guerra Mundial nos processos de consumismo.

Trata-se de um desvanecimento que foi gradual e que, atualmente, converte a gráfica popular em um elemento muito escasso, como caráter patrimonial crivado muitas vezes por reivindicações a partir da nostalgia. (Checa-Artasu e Rodríguez, 2009, p. 5).

Enquanto isso, a tradição do letreiramento popular enquanto manifestação da gráfica popular ainda continua bastante ativa em outros países. Checa-Artasu \& Rodríguez (2009) observam que:

$\mathrm{Na}$ América Latina, em países da África e na Índia, a gráfica popular ainda segue presente e ativa dentro do sistema comunicacional que se dá em uma cidade. Isso não quer dizer que não se deem as técnicas e os conceitos mais avançados do design gráfico nesses locais, porém parece que estes ganham espaço de forma mais lenta do que na Europa ou nos Estados Unidos, devido às condições econômicas, culturais e educacionais desses países. Tudo isso explica a sobrevivência massiva da chamada gráfica popular. (Checa-Artasu e Rodríguez, 2009, p. 6).

E essa presença ainda expressiva da gráfica popular no cenário de muitas cidades tem despertado o olhar de inúmeros pesquisadores, que, desde finais da década de 1990, começaram pouco a pouco a resgatar e valorizar essa produção e seus autores e/ou ainda tentar integrá-la à produção do design formal (Finizola, 2015, p. 50).

Na América Latina, é notável o surgimento de inúmeros projetos que buscam registrar e valorizar essa produção gráfica popular, nos quais a Internet, sem dúvida, desempenha um papel crucial para a difusão dessas ações e para o compartilhamento de informações sobre o tema.

\section{Método}

Para investigar a gráfica popular da América Latina e desenvolver uma pesquisa panorâmica sobre o tema, adotamos uma abordagem de pesquisa qualitativa de caráter exploratório. Dada a amplitude do universo de pesquisa, este projeto somente foi possível de ser realizado com apoio em uma rede colaborativa internacional de pesquisadores de diversos países da América Latina.

Os principais procedimentos técnicos envolveram pesquisas bibliográficas e em plataformas digitais sobre o tema; entrevistas com pesquisadores e profissionais da área; coleta de dados referentes à gráfica popular de cada localidade junto aos colaboradores; e o fichamento e a análise de todo o material coletado a fim de facilitar a compreensão do objeto de estudo e permitir o desenho de um panorama inicial sobre a gráfica popular na América Latina.

Para alcançar o propósito da pesquisa, enumeramos a seguir as principais fases do projeto, que ainda se encontra em fase de conclusão: 
Fase 1 | Mapeamento de projetos de resgate da gráfica popular

Fase 2 | Chamada para a colaboração de pesquisadores para participar da pesquisa

Fase 3 e 4 | Coleta e organização do material enviado pelos colaboradores - textos e fotos

Fase 5 | Elaboração de ficha de catalogação e análise da produção gráfica popular latina

Fase 6 | Análise e comparação dos dados coletados

Fase 7 | Resultados da análise

Fase 8 | Elaboração de relatório final do projeto de pesquisa

\section{Resultados}

Este artigo trata especificamente dos resultados obtidos na fase de mapeamento de projetos de resgate da gráfica popular identificados na América Latina. Nesse sentido, apresentaremos uma compilação das principais iniciativas identificadas a partir de levantamento realizado na Internet, em registros bibliográficos, bem como informações coletadas junto aos colaboradores de cada localidade.

Farret \& Pinto (2011, p. 31) observam que até hoje o conceito de América Latina é muito impreciso, "visto que é muito difícil determinar quais países a compõem ou quais os critérios utilizados para classificar este ou aquele país americano como integrante dessa denominação". Para o escopo deste trabalho, empregaremos a definição que é mais largamente reconhecida pelo senso comum e que define a América Latina como a região que abarca todos os países do continente americano, exceto os EUA e o Canadá, ou seja, os países da América do Sul, da América Central e o México, os quais têm como idiomas principais o português, o espanhol e diversas línguas indígenas.

$O$ resultado da fase de mapeamento gerou uma lista de 45 projetos/pesquisadores em atividade no período de 2000 a 2015, distribuídos em 14 países da América Latina [Tabela 1].

Tabela 1: Projetos de Registro da Gráfica Popular na América Latina em Curso entre 2000 e 2015 (Fonte: acervo pesquisa)

\begin{tabular}{l|l|l|l} 
Cód. & País & Projeto e/ou Pesquisador & $\begin{array}{l}\text { Colaborador } \\
\text { do Projeto }\end{array}$ \\
\hline 01 & Argentina & Ciudad Mutante, Mery Bargas & X \\
\hline & & El Libro de Los Colectivos, Julieta Ulanovsky & \\
\hline & & Fileteado Porteño, Alfredo Genovese & $\mathrm{X}$ \\
\hline 02 & Freddy Filete & $\mathrm{X}$ \\
\hline & & $\begin{array}{l}\text { Abridores de Letras de Pernambuco, Fátima Finizola, Damião } \\
\text { Santana e Solange Coutinho }\end{array}$ & $\mathrm{X}$ \\
\hline & Letras que Flutuam, Fernanda Martins e Sâmia Batista & \\
\hline & Tipografia Artesanal Urbana, Vinícius Guimarães & \\
\hline & Tipos Populares do Brasil, Pedro Moura & \\
\hline & Tipos Malditos, Marcelo Drummond & \\
\hline & $\begin{array}{l}\text { Tipografia Popular: potências do ilegível na experiência do } \\
\text { cotidiano, Bruno Guimarães Martins }\end{array}$ & \\
\hline & Seu Juca: letrista pernambucano, Priscila Lena Farias & \\
\hline & Tipo Brasilêro, Crystian Cruz & \\
\hline & $\begin{array}{l}\text { Design Gráfico Vernacular: a arte dos letristas, Fernanda de } \\
\text { Abreu Cardoso }\end{array}$ & \\
\hline & $\begin{array}{l}\text { Letreiros Populares do Recife: uma análise dos seus aspectos } \\
\text { semânticos e morfológicos, Mariana Hennes Sampaio }\end{array}$ & \\
\hline & $\begin{array}{l}\text { Tipografia Vernacular: os elementos tipográficos das letras do } \\
\text { sapateiro Alves, Juliana Lotif e Tarcísio Bezerra }\end{array}$ & \\
\hline & $\begin{array}{l}\text { Os pintores de letras: um olhar etnográfico sobre as inscrições } \\
\text { vernaculares urbanas, Marcus Dohmann }\end{array}$ & \\
\hline & $\begin{array}{l}\text { Pinturas de Paisagem Amazônica e a Construção de um } \\
\text { Imaginário da Cultura Popular, Mariana Bernd }\end{array}$ & \\
\hline & $\begin{array}{l}\text { Letras do Cotidiano: a tipografia vernacular na cidade de Belo } \\
\text { Horizonte, Emerson Nunes Eller }\end{array}$ & \\
\hline & Vialetrera, Fernando Flores Molina & \\
\hline & & & \\
\hline & & &
\end{tabular}

Anais do 9ํㅡㄹ Congresso Internacional de Design da Informação | CIDI 2019

Proceedings of the 9th Information Design International Conference

Anais do $9^{\circ}$ Congresso Nacional de Iniciação Científica em Design da Informação | CONGIC 2019

Proceedings of the $9^{\text {th }}$ Information Design Student Conference 


\begin{tabular}{|c|c|c|c|}
\hline & & Mano Suelta, Simon Ibañez Nuñez & $\mathrm{X}$ \\
\hline & & $\begin{array}{l}\text { Rescate de Tipografias Urbano Populares Chilenas, Luis } \\
\text { Rojas e José Soto }\end{array}$ & \\
\hline & & Micros: el final del recorrido, Manuel Córdova & \\
\hline & & Ojo al Charqui, Mariela Zuñiga & \\
\hline & & El Rey del Cartel, Paula Guajardo & \\
\hline \multirow[t]{2}{*}{04} & Colômbia & $\begin{array}{l}\text { Popular de Lujo, Esteban Ucrós, Roxana Martinez e Juan } \\
\text { Duque }\end{array}$ & $\mathrm{X}$ \\
\hline & & Rubén Egea Amador & $\mathrm{X}$ \\
\hline \multirow[t]{3}{*}{05} & Costa Rica & Iden-tica, Juan Betancourt e Claudio Corrales & $\mathrm{X}$ \\
\hline & & Alfredo Enciso & $\mathrm{X}$ \\
\hline & & $\begin{array}{l}\text { Grafitica: Grafica Popular Costarricense, Sussy Vargas e } \\
\text { Carolina Goodfellow }\end{array}$ & \\
\hline 06 & El Salvador & Proyecto 503, Marco Umaña & $\mathrm{X}$ \\
\hline \multirow[t]{2}{*}{07} & Equador & Ojo al Aviso, Ana Lucía Garcés e Manuel Kingman & $\mathrm{X}$ \\
\hline & & Gráfica Popular, Juan Lorenzo Barragán & \\
\hline 08 & Guatemala & Lettering Guatemala & \\
\hline 09 & Haiti & Amazing Barbershop, Richard Fleming & $\mathrm{X}$ \\
\hline \multirow[t]{4}{*}{10} & México & $\begin{array}{l}\text { Sensacional del Diseño Mexicano, Juan Carlos Mena, Oscar } \\
\text { Reyes e Deborah Holtz }\end{array}$ & $\mathrm{X}$ \\
\hline & & Don Rótulos, Alma Millán e Yareli Rodríguez & $\mathrm{X}$ \\
\hline & & Bardas de Baile, Patrícia Cué & \\
\hline & & Martin Checa-Artasu e Pilar Rodríguez & \\
\hline \multirow[t]{2}{*}{11} & Panamá & Panamatipo, Mateo Sanchis & \\
\hline & & My Name is Diablo Rojo, Shadow Froslass e colaboradores & \\
\hline \multirow[t]{2}{*}{12} & Peru & $\begin{array}{l}\text { Carga Máxima, Azucena del Carmen e Alinder Espada } \\
\text { Camones }\end{array}$ & $\mathrm{X}$ \\
\hline & & Ruta Mare, Yerfesson Huamán e Kelly Cuyubamba & \\
\hline 13 & $\begin{array}{l}\text { República } \\
\text { Dominicana }\end{array}$ & Flow Tropical, Maurice Sanchéz & $\mathrm{X}$ \\
\hline \multirow[t]{2}{*}{14} & Uruguai & Garrapiñada, Chino Augustin López & $\mathrm{X}$ \\
\hline & & MVD: Gráfica Popular de Montevideo, Guido Indij & \\
\hline
\end{tabular}

Entre os objetos de estudo da gráfica popular investigados pelos 45 projetos catalogados, destacam-se: letreiramentos populares em geral - com estilo impessoal ou mais autorais, elaborados tanto por pintores especialistas como não especialistas —, murais ilustrados, ornamentação e identificação de meios de transporte, peças publicitárias - para produtos, serviços e eventos - embalagens, jogos e ainda peças para a livre expressão pessoal ou religiosa. Apesar de os processos manuais que empregam o manejo do pincel serem mais largamente utilizados para a elaboração dessas peças, também se nota em menor escala o uso de outras técnicas de impressão/confecção, como a tipografia, a serigrafia, o estêncil e o corte de adesivos à mão livre.

Após a catalogação dos projetos, também enumeramos algumas categorias referentes aos principais produtos confeccionados por esses grupos no intuito de difundir e preservar a estética gráfica popular: [a] banco de imagens; [b] publicações (livros, revistas, artigos, etc.);

[c] sites, blogs, redes sociais; [d] exposições; [e] cursos e oficinas; [f] documentários; [g] produtos gráficos e tipográficos; [h] outros. 


\section{Rede de Pesquisadores do Projeto ${ }^{1}$}

Dentre os projetos catalogados, selecionamos cerca de 18 iniciativas para integrar a pesquisa. A escolha foi realizada considerando uma amostra diversa de países e de suas manifestações gráficas e, em segunda instância, a disponibilidade e o interesse do grupo em participar da rede da pesquisa. Apresentamos a seguir, de forma breve, um resumo sobre os pesquisadores e/ou projetos que foram integrados à rede de colaboradores da pesquisa.

\section{Ciudad Mutante, Argentina}

Ciudad Mutante é um projeto criado em 2009 por Mery Bargas no qual se associa o registro fotográfico de desenhos e tipografias do design popular urbano de Mar del Plata com uma análise sociológica dessas manifestações. Mery estuda licenciatura em Letras na Universidad Nacional de Mar del Plata e se dedica à fotografia e investigação sobre a identidade cultural particular dessa região. Em 2015, o projeto gerou a publicação do fanzine experimental Ciudad Mutante, Estética del Mal Gusto.

\section{Freddy Filete e Patrícia Salatino, Argentina²}

Alfredo Guillermo Fernández (Freddy Filete) é um pintor argentino adepto da técnica do fileteado tradicional. Em 1994, Freddy abre o seu primeiro ateliê de cartazes e peças publicitárias decorativas, onde começa a desenvolver um estilo particular de desenhos e letreiramentos para o seu trabalho comercial. Nos anos seguintes, transitou por Buenos Aires e Santa Fé, até se estabelecer em San Telmo a partir do ano 2000, onde teve a oportunidade de conviver com outros mestres fileteadores. Mais adiante se muda definitivamente para San Miguel. Suas mostras e oficinas de fileteado viajam pela Argentina e por outros países, compartilhando espaços e encontros com muralistas que promovem a arte pública. Infelizmente Freddy faleceu em 2017, com esse projeto ainda em curso. O material enviado para o acervo desta pesquisa foi elaborado em conjunto com Patrícia Salatino.

\section{Abridores de Letras de Pernambuco, Brasil}

O projeto Abridores de Letras de Pernambuco - um mapeamento da gráfica popular realizou uma extensa pesquisa visual por seis cidades do Estado de Pernambuco ao longo de mais de 5 anos. O seu objetivo principal foi realizar um mapeamento e a análise da produção de letreiramentos populares e da profissão do pintor letrista em Pernambuco, por meio do estudo comparativo entre as paisagens urbanas das cidades do Recife, de Gravatá, Caruaru, Arcoverde, Salgueiro e Petrolina. O projeto foi desenvolvido pela designer Fátima Finizola, em conjunto com os designers Damião Santana e Solange Coutinho. Dentre os produtos finais da pesquisa estão exposições itinerantes e um livro homônimo, premiado na $28^{\mathrm{a}}$ edição do Prêmio Design do Museu da Casa Brasileira, em $2^{\circ}$ lugar, na categoria de Trabalhos Publicados.

\section{Letras que Flutuam, Brasil}

Outra frente de pesquisa da gráfica popular brasileira nasceu na Região Norte do País com o trabalho da designer Fernanda Martins. Em 2004, a pesquisadora realizou um levantamento sobre os letreiramentos encontrados nos barcos do Rio Amazonas, fazendo um recorte sobre a produção que apresentava influências da estética vitoriana, peculiar em alguns estados da Região Norte. O trabalho rendeu novos frutos e se transformou no projeto cultural Letras que Flutuam em 2013, já com a colaboração de Sâmia Batista. Além de documentar essa produção por meio da elaboração de um vídeo, o projeto mapeou os artistas e promoveu exposições e oficinas de formação com os próprios habitantes ribeirinhos sobre o tema. Em 2018, o projeto ganhou o Prêmio Rodrigo de Melo Franco de Andrade, do Iphan, sendo reconhecido como a ação de patrimônio imaterial mais importante daquele ano.

\footnotetext{
1 Os dados apresentados são baseados em informações fornecidas diretamente pelos colaboradores por email. Aqueles extraídos de fontes externas apresentam a referência da fonte.

2 Fonte: García, 2009

Anais do 9 Congresso Internacional de Design da Informação | CIDI 2019

Proceedings of the 9th Information Design International Conference

Anais do $9^{\circ}$ Congresso Nacional de Iniciação Científica em Design da Informação | CONGIC 2019

Proceedings of the $9^{\text {th }}$ Information Design Student Conference 


\section{Vialetrera, Chile}

Vialetrera se propõe a fazer um passeio visual e histórico pelos letreiros artesanais da cidade de Antofagasta no Chile, em busca de revelar desde as pessoas que estão por trás dessa produção até as ruas onde os artefatos coexistem. O projeto é desenvolvido por Fernando Flores Molina, designer gráfico com foco em projetos de âmbito social e cultural que valorizam o caráter produtivo humano e que transmitem aspectos da cultura local na sua concepção.

\section{Mano Suelta, Chile}

O projeto Mano Suelta nasce em 2013 a partir da inquietação pessoal do designer Simon Ibañez Nuñez na busca de gerar um registro visual dos letreiros urbanos chilenos feitos à mão por meio da pintura, do desenho com marcadores ou de qualquer outra técnica análoga. $O$ projeto destaca o trabalho e o ofício do letrista - ou pintor de letras -, como artífice responsável pela criação desses atrativos códigos visuais. Sua intenção é elaborar uma perspectiva histórico-visual do letreiramento comercial e da gráfica vernacular a partir de registros fotográficos e audiovisuais do imaginário gráfico popular presente nas ruas, nos meios de transporte e nas zonas comerciais das principais cidades do Chile.

\section{Popular de Lujo, Colômbia ${ }^{3}$}

O coletivo Popular de Lujo, criado em 2003 na Colômbia, tem um extenso trabalho de divulgação e valorização da gráfica popular colombiana e de outros países. O grupo formado por Esteban Ucrós, Roxana Martinez e Juan Esteban Duque se dedica a documentar e investigar a gráfica popular e também a produzir exposições, oficinas, textos e conferências de forma a promover o trabalho dos rotulistas (denominação para designar o pintor de letras em alguns países latinos de língua espanhola).

\section{Rubén Egea Amador, Colômbia ${ }^{4}$}

O designer gráfico Rubén Egea Amador é professor-assistente da Universidade Jorge Tadeo Lozano - seccional do Caribe (Colômbia), e especialista em Teoria do Design Comunicacional pela FADU-UBA (Argentina), onde desenvolveu o projeto Circuito de Cultura Aplicado al "Cartel Picotero" de Cartagena das Índias. A pesquisa trata do estudo desse gênero da gráfica popular urbana de Cartagena - o cartel picotero - , utilizado largamente para suprir a necessidade de comunicação e divulgação dos toques de picó, fenômeno musical presente nas periferias locais.

\section{Iden-tica, Costa Rica ${ }^{5}$}

Na América Central, a linguagem gráfica popular e os personagens curiosos estampados nos muros de San José, na Costa Rica, chamaram a atenção do designer e fotógrafo venezuelanocosta-riquense Juan Manuel Betancourt. Em 2013, Betancourt criou o projeto Iden-tica, que nasceu com a intenção de registrar fragmentos da identidade gráfica costa-riquense presentes nos entornos urbanos da Costa Rica que definem a idiossincrasia do tico (sinônimo popular para o gentílico costa-riquense). Todas as imagens registradas por Betancourt e colaboradores, bem como artigos sobre a gráfica popular e contos sobre a vida cotidiana costa-riquense, compõem um divertido fanzine de publicação quadrimestral. Hoje, o projeto é desenvolvido em conjunto com o designer Claudio Corrales e também conta com contribuições de pesquisadores de países diversos da América Latina.

\section{Alfredo Enciso, Costa Rica ${ }^{6}$}

O peruano Alfredo Enciso vive na Costa Rica desde 2012, onde é fundador e diretor de arte do estúdio Pupila. Após concluir a universidade, durante suas viagens diárias a caminho do

\footnotetext{
${ }^{3}$ Fonte: Finizola, 2015.

${ }^{4}$ Fonte: DICOM, 2012.

${ }^{5}$ Fonte: Finizola, 2015.

${ }^{6}$ Fonte: Moya, 2015.
} 
trabalho, um estilo peculiar de tipografia empregada na elaboração de letreiramentos manuais para bares, mercearias, oficinas mecânicas, salões de beleza, entre outros estabelecimentos comerciais do centro de San José, despertou o seu interesse e sua curiosidade. A partir de 2009, Alfredo começou a documentar esse trabalho em conjunto com sua irmã, quando descobriu o autor das peças: Don Gerardo Picado, ou Mr. Masking, como o pintor é popularmente conhecido na localidade. $O$ trabalho de registro e investigação da obra do pintor de letras resultou na publicação de um livro em 2015, elaborado na intenção de prestar um tributo àquele que ele considera como "o primeiro tipógrafo" costa-riquenho.

\section{Proyecto 503, El Salvador}

Em El Salvador, a tradição popular de decorar de maneira artesanal e com um estilo gráfico peculiar os ônibus de transporte que viajam para o interior do país está se perdendo ou sendo substituída por uma prática mais cômoda e com menos identidade. O Proyeto 503 faz referência ao número de uma das rotas de ônibus, e ao mesmo tempo, ao código postal de El Salvador. Assim, a pesquisa desenvolvida por Marco Umaña tem a finalidade de registrar esse elemento da memória visual coletiva do seu país.

\section{Ojo al Aviso, Equador ${ }^{7}$}

No Equador, também encontramos algumas iniciativas para registrar a gráfica popular. Em 2008, Ana Lúcia Garcez e Manuel Kingman publicaram o livro Ojo al Aviso, onde apresentam não só uma coletânea fotográfica de letreiramentos populares equatorianos, mas também o depoimento de alguns pintores de letras que estão por trás dessa produção.

\section{Amazing Barbershop, Haiti ${ }^{8}$}

O projeto Amazing Barbershop, desenvolvido pelo escritor, artista e documentarista britânico Richard Fleming, caracteriza-se como uma exploração documental e um levantamento da arte da barbearia haitiana, incluindo uma investigação da cultura material e de aspectos sociológicos presentes na tradição da pintura manual para identificação de barbearias no Haiti. O acervo do projeto é composto por um banco de fotografias que celebram todas as manifestações dessa forma popular de arte gráfica, do urbano ao rural, das expressões mais ingênuas àquelas com um domínio hiper-real, produzidas por pintores exímios. Entrevistas com os artistas responsáveis também auxiliam na contextualização socioeconômica dessa ainda próspera tradição de sinalização pintada à mão em terras haitianas.

\section{Sensacional del Diseño Mexicano, México ${ }^{9}$}

Em 1996, surge no México o coletivo Sensacional del Diseño Mexicano, formado por Juan Carlos Mena, Oscar Reyes e Deborah Holtz, com o objetivo de promover a gráfica urbana e popular mexicana, que, apesar de estar afastada dos cânones estéticos das grandes escolas de design, tem seu expressivo valor. Desde então, o projeto registrou mais de 10 mil imagens da gráfica popular mexicana. Parte da coleção foi publicada em um livro homônimo com três volumes. Em 2012, o projeto também foi convertido em uma série de seis curtas-metragens. Hoje o coletivo se dedica à manutenção de uma grife de produtos inspirada na linguagem gráfica popular de seu país.

\section{Don Rótulos, México}

O projeto Don Rótulos se dedica a compartilhar a identidade popular mexicana, com a intenção de funcionar como meio de apoio e inspiração da produção local ou pelo simples prazer de ver e sentir a arte da pintura de letras, as cores e as ilustrações presentes pelas ruas do México. $O$ projeto é uma iniciativa de Alma Millán e Yareli Rodríguez.

\section{Carga Máxima, Peru}

\footnotetext{
7 Fonte: Finizola, 2015.

${ }^{8}$ Fonte: Fleming, 2016.

${ }^{9}$ Fonte: Finizola, 2015.
} 
Originários do coletivo Ruta Mare, a dupla peruana Azucena del Carmen e Alinder Espada fundaram em 2014 o seu próprio projeto - o Carga Máxima. A iniciativa busca a promoção da gráfica popular limenho-peruana, por meio da investigação e prática do estilo peruano de fazer letras, utilizando apenas o pincel e uma carga extra de tinta, colorido vibrante e fluorescente. $O$ coletivo trabalha com a produção de letreiros, layouts, logotipos e estampas inspirados no estilo dos letreiramentos populares peruanos. Também são oferecidos regularmente cursos de pintura de letras nos mais diversos países.

\section{Flow Tropical, República Dominicana ${ }^{10}$}

Flow Tropical é um projeto organizado por Maurice Sanchez que reúne um compêndio de fotografias que documentam as pinturas e os anúncios publicitários presentes nas paredes de diversos estabelecimentos comerciais - bares, restaurantes, boates, boutiques - de inúmeras cidades e lugarejos da República Dominicana. Maurice é publicitário, artista visual e fotógrafo, natural da cidade de Santo Domingo. Já participou de diversas exposições como artista e curador. As suas fotografias revelam as mais diversas manifestações estéticas da cultura popular atual da República Dominicana.

\section{Garrapiñada, Uruguai}

Garrapiñada é um projeto de investigação, difusão e resgate da gráfica popular na região do Rio da Prata, no Uruguai, desenvolvido por Agustín Chino López. Agustín é artista plástico, designer, ilustrador e escritor montevideano e apreciador das artes populares. Todas as fotos do projeto são de sua autoria. As redes sociais são a principal plataforma de divulgação do projeto.

\section{Considerações Finais}

A presente investigação contribui de forma mais ampla para o fortalecimento e reconhecimento da cultura gráfica popular no âmbito do design. Este artigo, particularmente, auxilia o registro histórico do movimento de resgate da produção gráfica popular da América Latina no início do século XXI, na forma de iniciativas de pesquisa no âmbito do design gráfico, design da informação e áreas afins. Pretende-se que os dados aqui compartilhados se configurem como uma fonte de consulta para pesquisadores da área, bem como uma base de dados inicial que possa ser continuamente ampliada.

Hoje, a maioria dos projetos de difusão dessa estética popular realizados nos países da América Latina são divulgados por meio de plataformas digitais - como sites e redes sociais — o que permitiu, nos últimos anos, uma troca intensa de informações, bem como ações colaborativas entre pesquisadores de localidades distintas, e ainda que líderes de projetos tivessem a oportunidade de se conhecer tanto de forma virtual como presencial. Um grupo de estudo intitulado Latinoamerica Vernacular também foi criado por meio do Facebook, como ambiente propício para o compartilhamento de informações e o contato constante entre essas pessoas, gerando uma troca de experiências sem precedentes sobre o tema.

Os resultados obtidos com a conclusão da etapa de mapeamento deste projeto atestam que, de fato, há um movimento forte de registro da memória gráfica popular em toda a América Latina, movimento este que ainda segue em expansão, visto que também presenciamos o surgimento de novos projetos com esse caráter, após o período de recorte temporal deste levantamento (2000-2015).

\section{Referências}

Checa-Artasu, M. M., \& Rodriguez, P. C. (2009). La Grafica Popular Mexicana: comu-nicación, diseño y paisaje urbano. Anais do Congresso da Associação de Estudos Latinoamericanos, Rio de Janeiro, 2009.

\footnotetext{
10 Fonte: Sanchez, 2015.

Anais do 9 Congresso Internacional de Design da Informação | CIDI 2019

Proceedings of the 9th Information Design International Conference

Anais do $9^{\circ}$ Congresso Nacional de Iniciação Científica em Design da Informação | CONGIC 2019

Proceedings of the $9^{\text {th }}$ Information Design Student Conference
} 
Finizola, M. F. W. \& Nuñez, S. I. | Proyecto Callejero: um panorama da gráfica popular na América Latina

Dicom (2012). Circuito de Cultura Aplicado al "Cartel Picotero" de Cartagena de Indias. Disponível em: http://maestriadicom.org. Acesso em: 10 de julho de 2019.

Farret, R. L., \& Pinto, S. R. (2011). América Latina: da construção do nome à consolidação da ideia. In: TOPOI, v. 12, n. 23. Rio de Janeiro: UFRJ. p. 30-42.

Finizola, M. F. W. (2015). A Tradição do Letreiramento Popular em Pernambuco: uma investigação acerca de suas origens, forma e prática. Tese de Doutorado. Recife: UFPE.

Fleming, R. A. (2016). Amazing Barbershop. Disponível em: http://www.inthefieldrecording.org/ under-renovation/amazing-barbershop/. Acesso em: 10 de julho de 2019.

García, C. L. (2009). La Siembra del Filete. Disponível em: http://freddyfilete.blogspot.com/. Acesso em: 10 de julho de 2019.

Moya, K. S. (2015). Mr. Masking: la obra de Gerardo Picado. San José: Pupila Estudio.

Sanchez, M. (2015). Flow Tropical. Santo Domingo, Ediciones De a Poco.

Ucrós, E. (2012). Popular de Lujo. Palestra apresentada na conferência What Design Can Do. Amsterdã. (Transcrição cedida pelo autor).

\section{Sobre o(a/s) autor(a/es)}

Fátima Finizola, Doutora em Design, Universidade Federal de Pernambuco, Brasil $<$ fatima.finizola@gmail.com>

Simon Ibañez Nuñez, Especialista em Lettering e Tipografia, Universidad de Chile, Chile <simonibaneznunez@gmail.com> 